\title{
Fertile Triploid Males-An Uncommon Case Among Hybrid Vertebrates
}

\author{
CARLA SOUSA-SANTOS $^{1 *}$, MARIA JOÃO COLLARES-PEREIRA ${ }^{2}$, \\ AND VITOR ALMADA ${ }^{1}$ \\ ${ }^{1}$ Instituto Superior de Psicologia Aplicada, Unidade de Investigação \\ em Eco-Etologia, Lisboa 1149-041, Portugal \\ ${ }^{2}$ Universidade de Lisboa, Faculdade de Ciencias, Centro de Biologia \\ Ambiental, Lisboa 1749-016, Portugal
}

\begin{abstract}
The endemic Iberian minnow Squalius alburnoides is a complex of fishes of hybrid origin including both males and females with distinct ploidy levels and varying proportions of the parental genomes. In this paper we demonstrated that in contrast to many vertebrate hybrid lineages the sperm of triploid hybrid males of $S$. alburnoides is viable and fully functional. Flow cytometry and analysis of sequences of a fragment of the beta-actin nuclear gene applied to progenitors and offspring evidenced that these males produced their sperm clonally, as already described for diploid hybrids. The presence of different types of fertile males (nonhybrid diploids with normal meiosis and both diploid and triploid hybrids) coupled with hybridogenetic meiosis in females endows this vertebrate complex with a high level of independence from other species and contributes to maintain its genetic variability. J. Exp. Zool. 307A:220-225, 2007. Wiley-Liss, Inc.
\end{abstract}

\footnotetext{
How to cite this article: Sausa-Santos C, Collares-Pereira MJ, Almada V. 2007. Fertile triploid males-An uncommon case among hybrid vertebrates. J. Exp. Zool. 307A: 220-225.
}

Often when two distinct species hybridize, there is a disruption of normal meiosis that leads to partial or total infertility of the descendants (Vrijenhoek, '89, '94). Some hybrids, however, overcome this problem by reproducing by diverse gametogenetic mechanisms. These alternative modes of reproduction among hybrid lineages of vertebrates are known to have evolved independently in many groups and may involve asexual or modified forms of sexual reproduction (reviewed in Dawley and Bogart, '89).

Within the fish family Cyprinidae, the small Iberian minnow Squalius alburnoides is an example of an ecologically extremely well-succeeded hybrid lineage that was originated by intergeneric crosses between Squalius pyrenaicus females-P genome - and males of a probably extinct paternal species-A genome (Alves et al., 2001), phylogenetically close to the extant Anaecypris hispanica (Robalo et al., 2006). This interesting female sex biased complex comprises diploid, triploid and tetraploid hybrid forms and a diploid nonhybrid form (AA) constituted almost exclusively by males (reviewed in Alves et al., 2001). This diploid AA male lineage contains two genomic complements inherited from the paternal ancestor but a pyrenaicus-like mtDNA (Alves et al., 2002), a clear indication that they resulted from the hybrids and are not "survivors" of the paternal progenitor of the complex. Instead of being a typical asexual all-female lineage that reproduces clonally, this complex includes also fertile males and has varied reproductive modes and gametogenetic processes.

Concerning the spermatogenetic processes, it is known that normal meiosis occurs in diploid nonhybrids (AA) and in balanced tetraploids (PPAA) and that on the contrary, diploid hybrids

Grant sponsor: FCT Pluriannual Program; Grant numbers: UI\&D 331/94 and UI\&D 329/94; Grant sponsor: FCT; Grant numbers: SFRH/ $\mathrm{BD} / 8320 / 2002$.

*Correspondence to: C. Sousa-Santos, Instituto Superior de Psicologia Aplicada, Unidade de Investigação em Eco-Etologia, Rua Jardim do Tabaco 34, 1149-041, Portugal.

E-mail: carla.santos@ispa.pt

Received 3 July 2006; Revised 26 October 2006; Accepted 16 December 2006

Published online 29 January 2007 in Wiley InterScience (www. interscience.wiley.com). DOI: 10.1002/jez.a.363. 
(PA) produce fertile unreduced sperm, transmitting the intact genome to the offspring (Alves et al., '98, '99). A study of two triploid males, which seem to be very rare in natural populations, by flow cytometry of the DNA content of erythrocytes and spermatozoa, showed that they also produced unreduced sperm (Alves et al., '99) but their genomic constitution (PAA or PPA) remained unknown and their sperm functionality was not tested.

Therefore, the aims of the present study were: (1) to clarify the reproductive mode and fertility of triploid males by accurately determining the genomic constitution of their sperm and of progeny using a suitable nuclear marker (betaactin gene) combined with ploidy confirmation; and (2) to evaluate the viability of the progeny produced by triploid males. To validate the applied methodology, crosses with diploid PA and AA males were also performed.

\section{MATERIALS AND METHODS}

Five $S$. alburnoides males (one triploid, two hybrid diploids and two nonhybrid diploids) were selected after the determination of their genomic constitutions by beta-actin gene sequencing and the confirmation of their ploidy by flow cytometry. These males were then used in crossing experiments with $S$. alburnoides and $S$. torgalensis females and their live progeny $(N=31)$ was subsequently analysed, also by beta-actin gene sequencing and flow cytometry. Although DNA nuclear measurements were impracticable in very small dead juveniles, the DNA content of 33 additional preserved juveniles was analysed since ploidy assessment was also possible through the analysis of the beta-actin gene sequences (see below). The ploidy of the $S$. torgalensis females was not determined since it is expected to be a diploid species like $S$. aradensis, $S$. carolitertii and S. pyrenaicus (Collares-Pereira and Moreira da Costa, '99). This was confirmed by the fact that of more than $25 \mathrm{~S}$. torgalensis sequenced for the beta-actin gene none gave indications of being nondiploid (unpublished data). Additional and more detailed methodological information is presented below.

\section{Assessment of the genomic constitutions}

When a nuclear gene of a hybrid between closely related species is sequenced, single nucleotide polymorphisms appear in chromatograms as single double peaks. However, in the case of a hybrid between species that differ by one or more indels in a particular gene fragment, the sequencing process generates artefacts in the resultant chromatograms that appear as series of false double peaks and it is possible to reconstruct the complements involved since the bases are out of phase for as many positions as the size of the indel-for more details see Sousa-Santos et al. (2005). This process of reconstruction of the genomes present in hybrids is favoured by a previous knowledge about some fixed mutations that are specific of the parental genomes as these act as reference points that make possible to ascribe unambiguously each peak to the correct parental genome (Sousa-Santos et al., 2005).

Thus, to evaluate the result of the spermatogenetic process of a $S$. alburnoides male through the observation of the genomic constitution of its progeny, it was considered ideal to cross the male with a female of a species having characteristic marker mutations absent in the male but sufficiently related to prevent reproductive isolation. This important role could be performed by S. torgalensis females from Mira River, where $S$. alburnoides complex is absent. Indeed, concerning the beta-actin gene of the Portuguese Squalius species, three groups of haplotypes were found so far, clearly distinct from each other by characteristic patterns of fixed mutations and indels (SousaSantos et al., 2005, 2006): P and C haplotypes in $S$. pyrenaicus and $S$. carolitertii (respectively); Q and T haplotypes in $S$. aradensis and $S$. torgalensis (respectively); and A haplotypes in S. alburnoides. At the beta-actin gene level, the $\mathrm{P}$ and $\mathrm{C}$ haplotypes are not distinguishable from each other and the same occurs between the $\mathrm{Q}$ and $\mathrm{T}$ haplotypes (Sousa-Santos et al., 2006). S. alburnoides hybrids exhibit a mixture of $\mathrm{A}$ and $\mathrm{P}, \mathrm{C}$ or $\mathrm{Q}$ haplotypes depending on whether they are, respectively, descendants of $S$. pyrenaicus, $S$. carolitertii or of $S$. aradensis, the three Squalius species with which S. alburnoides occurs in sympatry.

Since all S. alburnoides males selected to be used in the crossing experiments were from Tagus and Douro river basins (where $S$. pyrenaicus and $S$. carolitertii, respectively, occur in sympatry with $S$. alburnoides), they presented similar beta-actin haplotypes (P and C). Crossings with $S$. torgalensis bearing beta-actin T-haplotypes that are clearly distinct from $\mathrm{P}$ and $\mathrm{C}$ haplotypes would, therefore, allow an easy discrimination of the genomes inherited by the progeny, a situation that would not occur if the females used in the experiments were $S$. pyrenaicus or $S$. carolitertii 
since they would bear $\mathrm{P}$ and $\mathrm{C}$ haplotypes like the $S$. alburnoides male progenitors.

The count method described by Sousa-Santos et al. (2005) was applied to a segment of $176 \mathrm{bp}$ and the resultant $P$-count values were used to assess the ploidy and genome constitution of the $S$. alburnoides hybrids.

\section{Experimental crosses}

Each S. alburnoides male (one CAA triploid from the Douro River and two PA diploids from the Tagus River basin) was isolated with one S. torgalensis female (TT) from Mira River (crosses 1-3) in a tank (30l) with vegetation and coarse substratum, under natural conditions of light and temperature, for 2 months (May and June 2005). The spawning was not artificially induced and the experimental pairs spawned naturally, after which they were removed from the tank to minimize the loss of eggs and juveniles by predation. The majority of the eggs was lost due to fungal infections but a total of 31 juveniles was reared to the age of 8 months to attain a sufficiently large body length $(2-4 \mathrm{~cm})$ that allowed their survival after blood and fin clip sampling. A total of 33 juveniles that died during this period were immediately preserved in $96 \%$ ethanol.

In addition to these controlled experiments, two juveniles (9-months-old) resultant from group spawnings between seven $S$. alburnoides AA males from Tagus River and eight $S$. torgalensis females from Mira River and eight juveniles (21-monthsold) resultant from crosses between two AA males and two PA females of $S$. alburnoides from the Tagus river were also reared for comparative analyses (crosses 4 and 5). Due to their low number, only the beta-actin gene sequencing was performed since blood sampling of small fishes for flow cytometry procedures involves a high risk of mortality.

In total, considering the controlled experiments with only one pair of spawners and the experiments involving groups with more than one pair of spawners, 74 juveniles were sequenced which resulted from five crosses (two PAxTT, PAAxTT, AAxTT and AAxPA).

All the experiments were made in conformity to the ethical guidelines for animal care approved by the authors institutions.

\section{Laboratory methods}

Ploidy determination by flow cytometry was made using small blood samples drawn from the caudal vein of live juveniles or using fresh fin clips in the case of the adults used in the crossing experiments (since these measurements were made prior to the spawnings and the removal of fin clips involved less risks than blood sampling to the survival of the adults). The procedures used for blood samples were the ones described in Alves et al. ('99) and for the analysis of fin samples an adaptation of the method proposed by Lamatsch et al. (2000a) developed by M.J. Collares-Pereira et al. (unpublished) was used. The DNA content estimation for individual fishes followed the procedure described in Alves et al. ('99). Total genomic DNA was extracted from fin clips preserved in ethanol by an SDS/proteinase-k-based protocol, precipitated with isopropanol and washed with ethanol before re-suspension in water (adapted from Sambrook et al., '89). A total of $927 \mathrm{bp}$ of the beta-actin gene was amplified using the primer BACTFOR and conditions described in Robalo et al. (2006). Sequences were aligned with BioEdit $^{\mathbb{R}}$ (Ibis Therapeutics; Carlsbad, CA) v.5.0.6.

\section{RESULTS}

The analysis of the beta-actin gene sequences of the $S$. alburnoides males used in the crossing experiments that involved only one pair of spawners showed that they were all hybrids with both $\mathrm{P}$ and A complements. $P$-count values showed that males used in crosses 1 and 2 were diploids (PA genome) and that male of cross 3 was a triploid with a CAA genomic constitution. The flow cytometry analysis confirmed the ploidies of these three males (Table 1).

As shown in Table 1, all juveniles fathered by diploid hybrid males (crosses 1 and 2 ) were triploids with a TPA genomic constitution $(N=43)$. The descendants of the triploid male (cross 3 ) were all tetraploids with a TCAA genome $(N=21)$. This means that the sperm produced by the diploid and triploid males was also diploid and triploid, respectively. For the 31 offspring for which we had data from beta-actin sequencing and flow cytometry the results showed, without exception, full concordance between the two approaches.

Live progeny that have resulted from these three crosses reached 1 year of age and are still currently exhibiting an apparently normal development. These juveniles are being kept alive in order to try to evaluate their fertility and gametogenetic mechanisms.

Concerning the experimental crosses that involved more than one pair of spawners (crosses 
TABLE 1. Genomic constitution and ploidy of the males used in the controlled crossing experiments and their respective progenies inferred by flow cytometry (DNA content of erythrocytes and/or fin cells) and beta-actin nuclear gene sequencing (P-counts) analyses

\begin{tabular}{lllll}
\hline & & Cross 1 & Cross 2 & Cross 3 \\
\hline S. alburnoides male & $P$-count & $53.39 \%$ & $61.02 \%$ & $14.41 \%$ \\
& Erythrocytes (pg/cell) & 2.68 & 2.73 & 3.85 \\
& Inferred ploidy/genome & $2 n / \mathrm{PA}$ & $2 n / \mathrm{PA}$ & $3 n / \mathrm{CAA}$ \\
& & & $24(16 / 8)$ & $27(13 / 8)$ \\
Juveniles & $N$ (live/preserved) & $19(2 / 17)$ & $89.70 \% \pm 1.90(N=19)$ & $94.55 \% \pm 2.36(N=24)$ \\
& $P$-count & $3.80 \pm 0.25$ & $3.68 \pm 0.12$ & $5.23 \pm 0.22$ \\
& Erythrocytes (pg/cell) & $(N=2)$ & TPA & $(N=13)$ \\
& Mean \pm SD & TPA & TCAA \\
\hline
\end{tabular}

All crosses were mothered by S. torgalensis females (TT genome). P, C and A beta-actin haplotypes were inherited from the male progenitors. Flow cytometry reference values: $2.44 \pm 0.08 \mathrm{pg} /$ cell for diploids, $3.64 \pm 0.16 \mathrm{pg} / \mathrm{cell}$ for triploids and $4.83 \pm 0.08$ for tetraploids (Alves et al., '99). $P$-count reference values: $55.77 \% \pm 6.88$ for diploids and balanced tetraploids and $95.69 \%$ for PPA triploids (Sousa-Santos et al., 2005).

4 and 5), both groups involved S. alburnoides males with an AA genome (mean $2.65 \pm 0.10 \mathrm{pg} /$ cell, $N=7$; and mean $2.67 \pm 0.21 \mathrm{pg} / \mathrm{cell}, N=2$, respectively). In cross 4 the nonhybrid males fertilized the eggs of $S$. torgalensis females and the resulting progeny was constituted by diploid TA hybrids $(P$-count $=64.41 \% \pm 3.60, N=2)$. In cross 5, the nonhybrid males mated with $S$. alburnoides females with a PA genome (mean $2.54 \pm 0.01 \mathrm{pg} / \mathrm{cell}$ and $P$-count $=58.47 \% \pm 1.20$, $N=2$ ) and the resulting progeny was triploid and exhibited a PAA genome $(P$-count $=5.93 \% \pm 1.81$, $N=8$ ). This means that in both crosses, the AA males produced haploid sperm which fertilized, respectively, haploid eggs from the $S$. torgalensis females and diploid eggs from $S$. alburnoides PA females (as expected since meiosis does not occur in this type of females, as described by Alves et al., '98).

\section{DISCUSSION}

The occurrence of triploid vertebrates is considered to be a rare phenomenon and is generally coupled with infertility or, more rarely, with asexuality in allotriploids, since normal meiosis is likely to be disrupted by cytological mechanisms that preclude synapsis between heterospecific chromosomes (Dawley, '89; Stöck et al., 2002). Thus, the establishment and survival of these organisms depends on clonal reproductive modes such as parthenogenesis or gynogenesis; on the incorporation of unusual meiotic mechanisms (like hybridogenesis) that allow recombination to occur in triploid females, often with the exclusion of the genetic complement inherited from the male parent; and/or on the ploidy elevation by the incorporation of additional genomic material (processes detailed in Dawley, '89; Avise et al., '92; Vrijenhoek, '94; Beukeboom and Vrijenhoek, '98; Alves et al., 2001; Scali et al., 2003; Bi and Bogart, 2006).

Triploid males of several species often develop testes and successfully complete spermatogenesis but are in general sterile due to the production of aneuploid and/or abnormally shaped spermatozoa, although some may produce functional sperm and generate embryos with a very low survival rate. The sterility of triploid male fishes has been documented for both artificially induced triploids [e.g., Rhodeus ocellatus ocellatus (Kawamura et al., '99), Carassius auratus (Gui et al., '92), Verasper moseri (Mori et al., 2006), Salvelinus fontinalis (Allen and Stanley, '78) and Oncorhynchus mykiss (Thorgaard and Gall, '79)] and for naturally occurring individuals, whose triploidy resulted from the incorporation of additional genomic material by an unreduced egg [e.g., Misgurnus anguillicaudatus (Matsubara et al., '95; Zhang and Arai, '99; Oshima et al., 2005), Poecilia formosa (Lamatsch et al., 2000b) and Tinca tinca (Flajshans et al., '93)].

In contrast, the results presented in this study showed that a triploid CAA $S$. alburnoides male produced unreduced sperm (like the diploid PA males) which, after fertilization of haploid eggs from $S$. torgalensis, gave rise to viable tetraploid offspring. The fertilization by the unreduced sperm of these triploid males leads to ploidy elevation of the offspring, as described by Bogart et al. ('89) for hybrid salamanders of the genus Ambystoma. Interestingly, however, this process does not seem to increase indefinitely the maximum number of chromosomes of the complex 
since females seem to act as regulators of the ploidy level. Indeed, triploid $S$. alburnoides females, the most abundant form in natural populations, exhibit a mechanism of gamete production (meiotic hybridogenesis) that constitutes a limitation to an uncontrolled growth of the ploidy level: the ability to exclude the unmatched set of chromosomes is likely to enable, in general, a subsequent normal meiosis and the production of haploid eggs. The same type of reduction to a haploid stage was observed in fertile triploid males of the Batura toads all-triploid species Bufo pseudoraddei baturae (Stöck et al., 2002), in the water frog Rana esculenta triploid males (Graf and Pelaz, '89) and in Rana nigromaculata-lessona triploid males (Ohtani, '92).

Triploid males of $S$. alburnoides, however, seem to produce only clonal sperm as do $S$. alburnoides hybrid diploids (Alves et al., '99). Normal meiosis occurs only in $S$. alburnoides males that are nonhybrids and in tetraploids with balanced doses of both genomes (Alves et al., 2001). It must be bared in mind, however, that the number of males used in this study was very small and although likely representative of the more typical situation does not allow to entirely exclude other gametogenetic processes. The example of PAA females illustrates well the need for further investigation of the gamete formation in $S$. alburnoides: although they frequently produce haploid A eggs after exclusion of the P-genome followed by normal meiosis, the same individual may also produce diploid $\mathrm{AA}$ and triploid PAA gametes (Alves et al., 2004), stressing the instability of the process. The same type of instability cannot be ruled out in hybrid males with the available data. In addition, the gametogenetic behaviour of other types of males like PPA and PAAA is still awaiting investigation.

The fertility of the S. alburnoides males coupled with the ability of triploid females to undergo hybridogenetic meiosis is certainly an important factor contributing to the ecological success of the complex since it expands the number of possible routes to recombination and genetic variation. This scenario corroborates the point of view of several authors that highlighted the evolutionary potential of hybridization (e.g., Vrijenhoek, 2006). Indeed, instead of being necessarily "evolutionary dead-ends" (Dawley, '89) due to difficulties to escape the accumulation of deleterious mutations and to cope with the changing environment, hybrid complexes may experience genetic diversification that enhances their hypotheses of success (e.g., Dawley, '89; Vrijenhoek, '94; Dowling and Secor, '97; Alves et al., 2001; Stöck et al., 2002; Scali et al., 2003; Janko et al., 2005; Bi and Bogart, 2006; Gromicho et al., 2006).

In contrast with the majority of the vertebrate hybrid complexes already described, the $S$. alburnoides complex is neither a typical asexual lineage (as described by Dawley, '89) nor is it dependent on a bisexually reproducing host. Instead, this complex of minnows is constituted by both fertile males and females involved in varied reproductive modes that enhance its genetic variation, being an amazing example of the creative role that interspecific hybridization may play in evolution.

\section{ACKNOWLEDGMENTS}

The authors thank G. Lemos, Sousa-Santos family, J. Robalo and T. Bento for help in the maintenance of the fish tanks and rearing juveniles. We are also grateful to C. Carvalho, $\mathrm{M}$. Gromicho and L. Moreira da Costa for technical assistance with flow cytometry. DGF provided permissions for field work.

This study was funded by the FCT Pluriannual Program (UI\&D 331/94 and UI\&D 329/94) (FEDER participation). C. Sousa-Santos was supported by a PhD grant from FCT (SFRH/BD/8320/2002).

\section{LITERATURE CITED}

Allen SK, Stanley JG. 1978. Reproductive sterility in polyploidy brook trout, Salvelinus fontinalis. Trans Am Fish Soc 107:473-478.

Alves MJ, Coelho MM, Collares-Pereira MJ. 1998. Diversity in the reproductive modes of females of the Rutilus alburnoides complex (Teleostei, Cyprinidae) as determined by analysis of cytochrome $b$ sequences. Evolution 51: 1584-1592.

Alves MJ, Coelho MM, Próspero MI, Collares-Pereira MJ. 1999. Production of fertile unreduced sperm by hybrid males of the Rutilus alburnoides complex (Teleostei, Cyprinidae): an alternative route to genome tetraploidization in unisexuals. Genetics 151:277-283.

Alves MJ, Coelho MM, Collares-Pereira MJ. 2001. Evolution in action through hybridization and polyploidy in an Iberian freshwater fish: a genetic review. Genetica 111:375-385.

Alves MJ, Collares-Pereira MJ, Dowling TE, Coelho MM. 2002. The genetics of maintenance of an all-male lineage in the Squalius alburnoides complex. J Fish Biol 60:649-662.

Alves MJ, Gromicho M, Collares-Pereira MJ, Crespo-Lopez E, Coelho MM. 2004. Simultaneous production of triploid and haploid eggs by triploid Squalius alburnoides (Teleostei: Cyprinidae). J Exp Zool A 301:552-558.

Avise JC, Quattro JM, Vrijenhoek RC. 1992. Molecular clones within organismal clones: mitochondrial DNA phylogenies and the evolutionary history of unisexual vertebrates. Evol Biol 26:225-246. 
Beukeboom LW, Vrijenhoek RC. 1998. Evolutionary genetics and ecology of sperm-dependent parthenogenesis. J Evol Biol 11:755-782.

Bi K, Bogart JP. 2006. Identification of intergenomic recombinations in unisexual salamanders of the genus Ambystoma by genomic in situ hybridization (GISH). Cytogenet Genome Res 112:307-312.

Bogart JP, Elinson R, Licht LE. 1989. Temperature and sperm incorporation in polyploidy salamanders. Science 246: $1032-1034$.

Collares-Pereira MJ, Moreira da Costa L. 1999. Intraspecific and interspecific genome size variation in Iberian Cyprinidae and the problem of diploidy and polyploidy, with review of genome sizes within the family. Folia Zool 48: 61-76.

Dawley RM. 1989. An introduction to unisexual vertebrates. In: Dawley RM, Bogart JP, editors. Evolution and ecology of unisexual vertebrates. Bulletin 466. Albany: NY State Museum. p 1-28.

Dawley RM, Bogart JP, editors. 1989. Evolution and ecology of unisexual vertebrates. Bulletin 466. Albany: NY State Museum.

Dowling TE, Secor CL. 1997. The role of hybridization and introgression in the diversification of animals. Annu Rev Ecol Syst 28:593-619.

Flajshans M, Kvasnicka P, Ráb P. 1993. Genetic studies in tench (Tinca tinca L.): high incidence of spontaneous triploid. Aquaculture 110:243-248.

Graf J-D, Pelaz MP. 1989. Evolutionary genetics of the Rana esculenta complex. In: Dawley RM, Bogart JP, editors. Evolution and ecology of unisexual vertebrates. Bulletin 466. Albany: NY State Museum. p 289-301.

Gromicho M, Countanceau J-P, Ozouf-Costaz C, CollaresPereira MJ. 2006. Contrast between extensive variation of $28 \mathrm{~S}$ rDNA and stability of $5 \mathrm{~S}$ rDNA and telomeric repeats in the diploid-polyploid Squalius alburnoides complex and in its maternal ancestor Squalius pyrenaicus (Teleostei, Cyprinidae). Chromosome Res 14: 297-306

Gui JF, Jia J, Liang SC, Jiang YG. 1992. Meiotic chromosome behaviour in male triploid transparent coloured crucian carp Carassius auratus. J Fish Biol 41:317-326.

Janko K, Culling MA, Ráb P, Kotlík P. 2005. Ice age cloningcomparison of the Quaternary evolutionary histories of sexual and clonal forms of spiny loaches (Cobitis; Teleostei) using the analysis of mitochondrial DNA variation. Mol Ecol 14:2991-3004.

Kawamura K, Ueda T, Aoki K, Hosoya K. 1999. Spermatozoa in triploids of the rosy bitterling Rhodeus ocellatus ocellatus. J Fish Biol 55:420-432.

Lamatsch DK, Steinlein C, Schmid M, Schartl M. 2000a. Noninvasive determination of genome size and ploidy level in fishes by flow cytometry: detection of triploid Poecilia formosa. Cytometry 39:91-95.

Lamatsch DK, Nanda I, Epplen JT, Schmid M, Schartl M. 2000b. Unusual triploid males in a michrochromosome- carrying clone of the amazon molly, Poecilia formosa. Cytogenet Genome Res 91:148-156.

Matsubara K, Arai K, Suzuki R. 1995. Survival potential and chromosomes of progeny of triploid and pentaploid females in the loach, Misgurnus anguillicaudatus. Aquaculture 131: $37-48$.

Mori T, Saito S, Kishioka C, Arai K. 2006. Aquaculture performance of triploid barfin flounder Verasper moseri. Fish Sci 72:270-277.

Ohtani H. 1992. Mechanism of chromosome elimination in the hybridogenetic spermatogenesis of allotriploid males between Japanese and European water frogs. Chromosoma 102:158-162.

Oshima K, Morishima K, Yamaha E, Arai K. 2005. Reproductive capacity of triploid loaches obtained from Hokkaido Island. Ichthyol Res 52:1-8.

Robalo J, Sousa-Santos C, Levy A, Almada VC. 2006. Molecular insights on the taxonomic position of the paternal ancestor of the Squalius alburnoides hybridogenetic complex. Mol Phylogenet Evol 39:276-281.

Sambrook J, Fritsch EF, Maniatis T. 1989. Molecular cloning: a laboratory manual. New York: Cold Spring Harbor.

Scali V, Passamonti M, Marescalchi O, Mantovani B. 2003. Linkage between sexual and asexual lineages: genome evolution in Bacillus stick insects. Biol J Linn Soc 79: 137-150.

Sousa-Santos C, Robalo JI, Collares-Pereira MJ, Almada VC. 2005. Heterozygous indels as useful tools in the reconstruction of DNA sequences and in the assessment of ploidy level and genomic constitution of hybrid organisms. DNA Sequence 16:462-467.

Sousa-Santos C, Collares-Pereira MJ, Almada VC. 2006. Evidence of extensive mitochondrial introgression with nearly complete substitution of the typical Squalius pyrenaicus-like mtDNA of the Squalius alburnoides complex (Cyprinidae) in an independent Iberian drainage. J Fish Biol 68:292-301.

Stöck M, Lamatsch DK, Steinlein C, Epplen JT, Grosse W-R, Hock R, Klapperstück T, Lampert KP, Scheer U, Schmid M, Schartl M. 2002. A bisexually reproducing all-triploid vertebrate. Nat Genet 30:325-328.

Thorgaard GH, Gall GAE. 1979. Adult triploids in a rainbow trout family. Genetics 93:961-973.

Vrijenhoek RC. 1989. Genetic and ecological constraints on the origins and establishment of unisexual vertebrates. In: Dawley RM, Bogart JP, editors. Evolution and ecology of unisexual vertebrates. Bulletin 466. Albany: NY State Museum. p 24-31

Vrijenhoek RC. 1994. Unisexual fish: model systems for studying ecology and evolution. Annu Rev Ecol Syst 25:71-96.

Vrijenhoek RC. 2006. Polyploid hybrids: multiple origins of a treefrog species. Curr Biol 16:R245-R247.

Zhang Q, Arai K. 1999. Distribution and reproductive capacity of natural triploid individuals and occurrence of unreduced eggs as a cause of polyploidization in the loach, Misgurnus anguillicaudatus. Ichthyol Res 46:153-161. 